\title{
Studies of the structure and properties of materials of the Fe-C-Si system after centrifugation of the melt
}

\author{
Rinat Bikulov ${ }^{1, *}$ \\ ${ }^{1}$ Kazan Federal University, Naberezhnye Chelny Institute
}

\begin{abstract}
The paper presents the results of a study of the specifics of transformations in materials of the Fe-C-Si system (cast irons) during centrifugation of the melt and subsequent crystallization. The results of the study showed that the thermodynamic potential of compact graphitization can be created artificially, not only through the introduction of modifiers, but also due to the redistribution of impurities as a result of centrifugation.
\end{abstract}

The study of the specificity of structural transformations in materials based on the Fe-C-Si system during centrifugation of the melt and subsequent crystallization was performed on the blanks shown in Figure 1[1].

Figure 2 shows the experimental setup for centrifuging a melt in a crucible located in an induction furnace based on the KM 140-2 installation.

The installation is an adjustable frequency converter, the load of which is a crucible placed in an inductor. The inductor is cooled by water. The inductor is made of a copper pipe coated inside and outside with a polymer coating. Water can be connected to the water supply network or to an autonomous water supply system. The power supply of the installation is connected to a standard $220 \mathrm{~V}$ Euro-socket, which has a grounding contact and provides a load power of $2 \mathrm{~kW}$.

Inside the inductor (3) there is a heat-insulating insert (2), in which a graphite support (5) with a crucible is placed. The heat-insulating insert (lining) separates the cold inductor and the crucible heated to high temperature. Since the stand is graphite, and graphite is a conductor, it is heated by the induction currents induced by the inductor. To preserve heat, the installation is covered with a removable refractory heat-insulating ceramic cover. Outside, the inductor is closed by a collapsible protective casing. This design eliminates air flow, reduces heat loss, burning of the crucible and makes it possible to use argon for melting.

Inside the inductor (3) there is a heat-insulating insert (2), in which a graphite support (5) with a crucible is placed. The heat-insulating insert (lining) separates the cold inductor and the crucible heated to high temperature. Since the stand is graphite, and graphite is a conductor, it is heated by the induction currents induced by the inductor. To preserve heat, the installation is covered with a removable refractory heat-insulating ceramic cover. Outside, the inductor is closed by a collapsible protective casing. This design eliminates air

${ }^{*}$ Corresponding author : bikulov_uvr@mail.ru 
flow, reduces heat loss, burning of the crucible and makes it possible to use argon for melting.

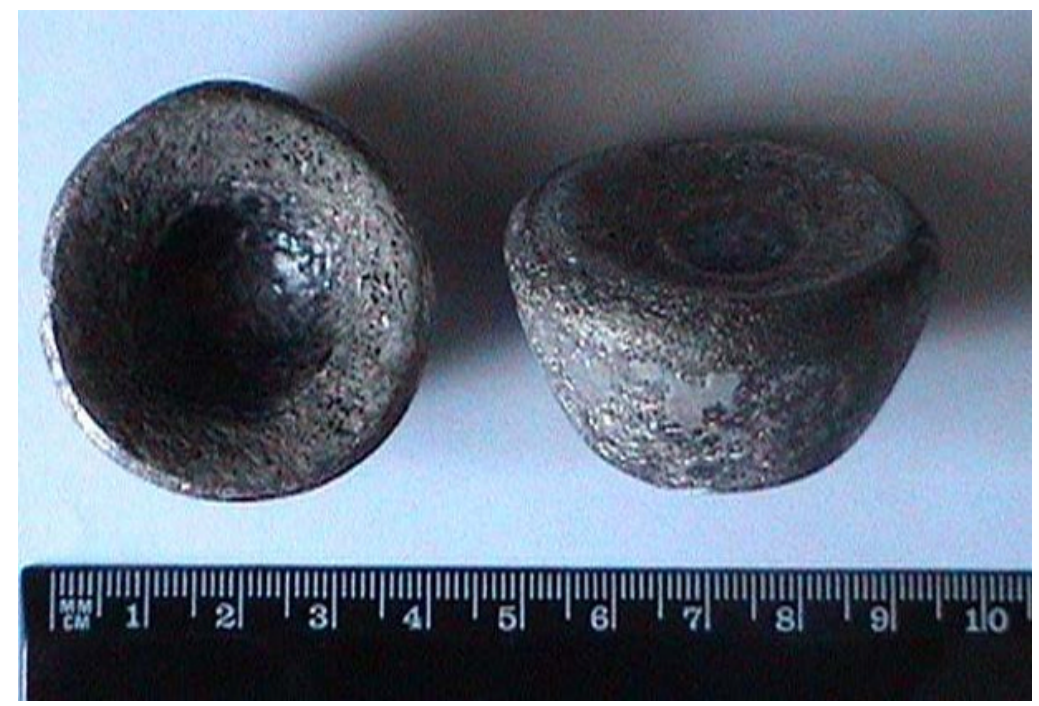

Fig. 1. Samples obtained by centrifugation.

For ease of maintenance (replacement of the lining, extraction of metal droplets, etc.) the melting chamber of the induction installation is made collapsible, providing access to the inductor.

The crucible with the molten liquid metal is removed using special forceps. In case of exceeding the permissible power sound alarm is activated and flashes "Overload", it is necessary to reduce the power level. In order to protect the inductor against overheating control is used water cooling flow and temperature. Protection automatically disables the installation by reducing the flow of coolant or failure of the water supply (indicator is flashing "Water"). In the event of overheating of the coolant above $70^{\circ} \mathrm{C}$, with working plant automatically reduces the power and sound alarm is activated.

Crucibles with alloy samples were covered with ground synthetic slag having the following chemical composition, weight. \%: $\mathrm{A}_{2} \mathrm{O}_{3}-49 ; \mathrm{CaO}-43 ; \mathrm{CaC}_{2}-4 ; \mathrm{A}_{4} \mathrm{C}_{3}-4$.

An argon flowing atmosphere was created inside the furnace space with an argon flow rate of about $200 \mathrm{~cm} 3 / \mathrm{min}$. The mass of the metal was $180 \mathrm{~g}$, and the initial mass of slag $7 \%$ of the mass of metal $-12.6 \mathrm{~g}$.

The metal melt was kept at a temperature of $1893 \ldots 1923 \mathrm{~K}\left(1620 \ldots 1650{ }^{\circ} \mathrm{C}\right)$ for 20 minutes. The melt temperature before rotation was measured by immersed tungstenrhenium thermocouple BP (A) 5/20 (graduation No. 3 with a diameter of thermoelectrodes $0.5 \mathrm{~mm}$ ) in a protective alundum cap. The use of a standard temperature control unit in combination with a KSP-4 rheostat device, which changes the value of the thermocouple signal installed in the immediate vicinity of the heater, ensured the temperature stabilization accuracy of $\pm 0.1 \mathrm{~K}\left({ }^{\circ} \mathrm{C}\right)$.

After stabilization of the thermal regime, but before the crucible was brought into rotation, the thermocouple was removed from the metal and subsequently focused on the readings of an external thermocouple-regulator that measures the temperature above the metal surface. After melting the metal and stabilizing the temperature (1873 K), the crucible was put into rotation at a speed of $1140 \mathrm{rpm}$. The metal surface in this case took the form of a paraboloid of revolution. In the steady state of rotation, pieces of slag were introduced into the metal hole and a "slag" paraboloid was induced in the center of the “metal” paraboloid. 


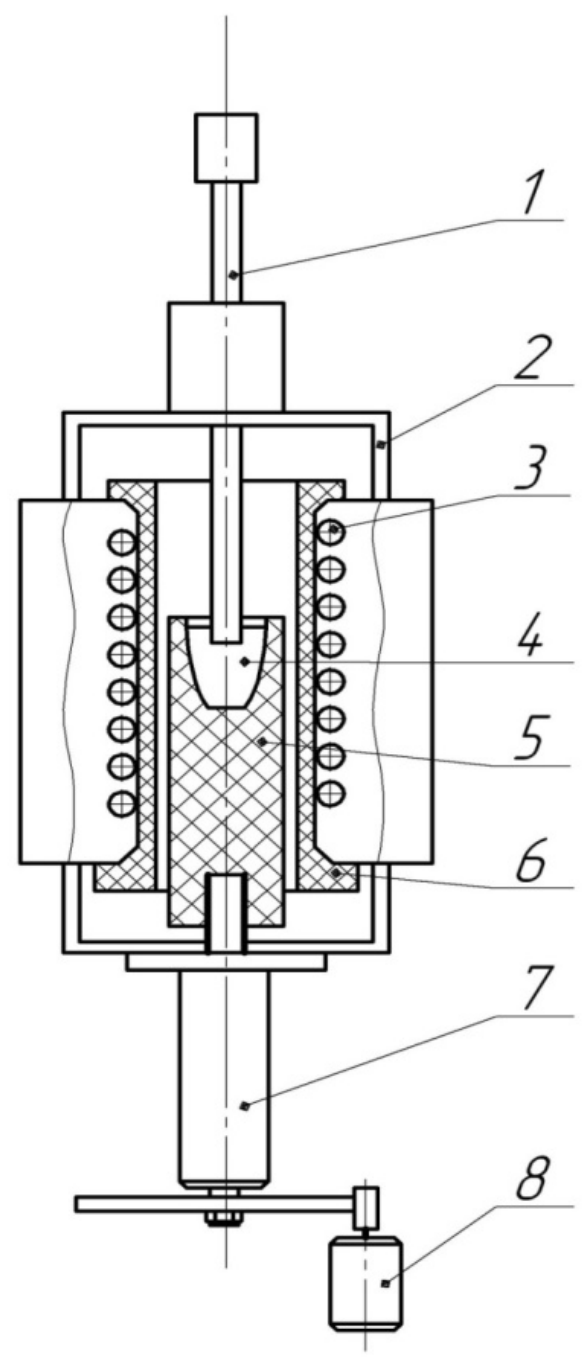

Fig. 2.Installation diagram for centrifuging the melt: 1- rod for dumping samples and measuring temperature; 2- heat-insulating cover; 3 - inductor; 4- crucible; 5- graphite stand; 6 - heatinsulating insert; 7- crucible rotation system; 8- electric motor.

Then, melted slag of a known chemical composition was introduced into a crucible with a melt, followed by stirring of the metal and slag for 40 minutes at a temperature of $1873 \mathrm{~K}$.

After that, the furnace was turned off and cooled in an argon atmosphere. After cooling, the alloy and slag were carefully separated from each other and from the crucible material and chemical analysis of the samples was carried out. Also, the samples were cooled in air.

In type tests, a hypereutectic synthetic cast iron was subjected to centrifugation, of the following composition: C - $5.0 \ldots 5.2 \%$, Si - $2.6 \ldots 2.3 \%$, Mn $<0.4 \%, \mathrm{Cr}<0.1 \%, \mathrm{P}<0.06 \%$, $\mathrm{S}<0.015 \%$. To prepare microsections, the workpiece was cut symmetrically along the axis of rotation into two parts. The microstructure was studied parallel to the axis along the entire height of the workpiece at equal intervals in characteristic zones: at the surface, the middle and inner parts of the workpieces (three zones A, B, C - Figure 3). 


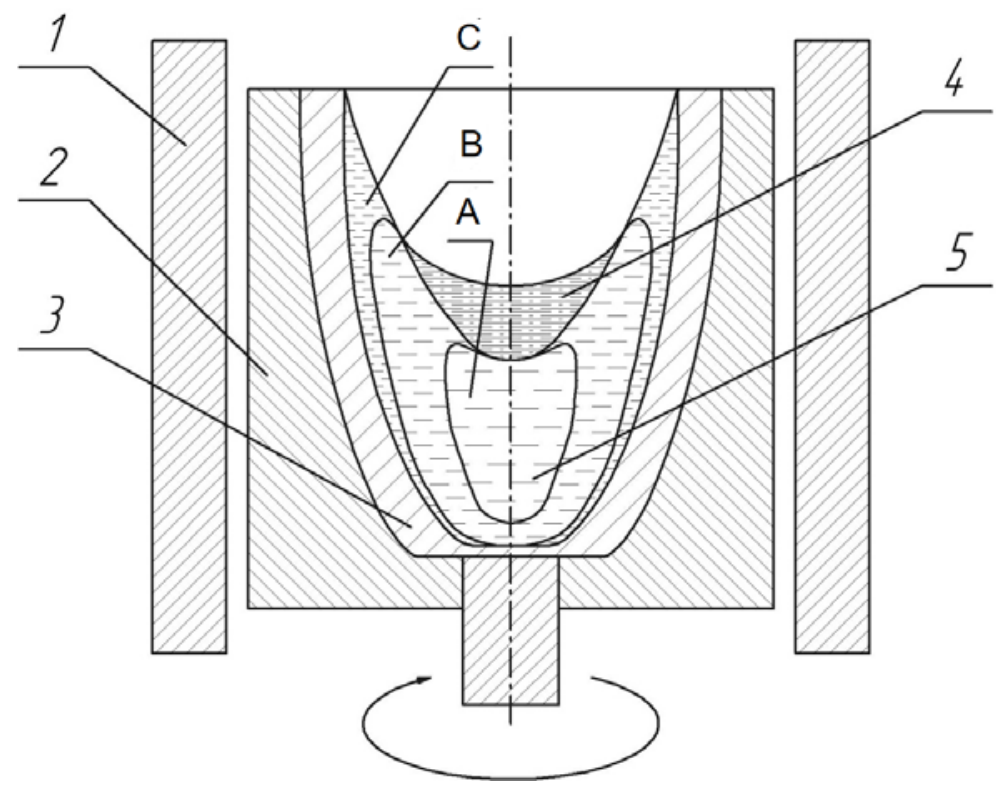

Fig. 3. Scheme of the experimental cell: 1- insulating insert; 2 - graphite stand; 3 - alundum crucible; 4 - slag; 5 - molten material based on the Fe-C-Si system; A, B, C - microstructure research areas.

In typical modes of centrifugation duration is $2400 \mathrm{~s}$; rotational speed $200 \mathrm{rpm}$; melt temperature $1873 \mathrm{~K}$.

The results of the study of the microstructure of materials based on the system Fe-C-Si after centrifugation indicate the complex nature of the processes occurring at the height of the ingot.

Established characteristic features of structure formation due to the regularities of mass transfer and crystallization of materials on the basis of the system Fe-C-Si during centrifugation. The simulation results of these processes are in good agreement with studies of the microstructure and chemical composition across the width of the ingot after centrifugation [2]. The microstructure of the ingot after centrifugation for 2400 with and subsequent crystallization in a furnace neodnorodnoe (figure 4).

In section $\mathrm{A}$, in the area located near the open surface of the ingot, large accumulations of lamellar graphite with particle sizes of $50 \ldots 200 \mu \mathrm{m}$ are observed. The matrix is a plate perlite with inclusions of ferrite up to $30 \%$. As the ingot approaches zone B, coarse-grained graphite (PG> 12) passes into the shallow-grained zone swirling graphite (PGF2). In this case, the matrix consists of lamellar perlite and ferrite. Along with large lamellar graphite inclusions, smaller ones with a swirling shape are observed (zone B). The matrix consists mainly of perlite and ferrite type PHF2.

An analysis of the chemical composition of materials based on the $\mathrm{Fe}-\mathrm{C}-\mathrm{Si}$ system over the height of the ingot indicates significant changes in the concentration of impurities that occurred during centrifugation of the melt. Thus, the carbon content from the bottom to the surface of the ingot varies from $3.00 \%$ (zone A) to $6.4 \%$ (zone A). The high carbon content in zone A, located near the surface of the ingot, is due to the "emergence" of the released graphite particles from the bottom of zone A and B, especially during slow cooling during centrifugation. 

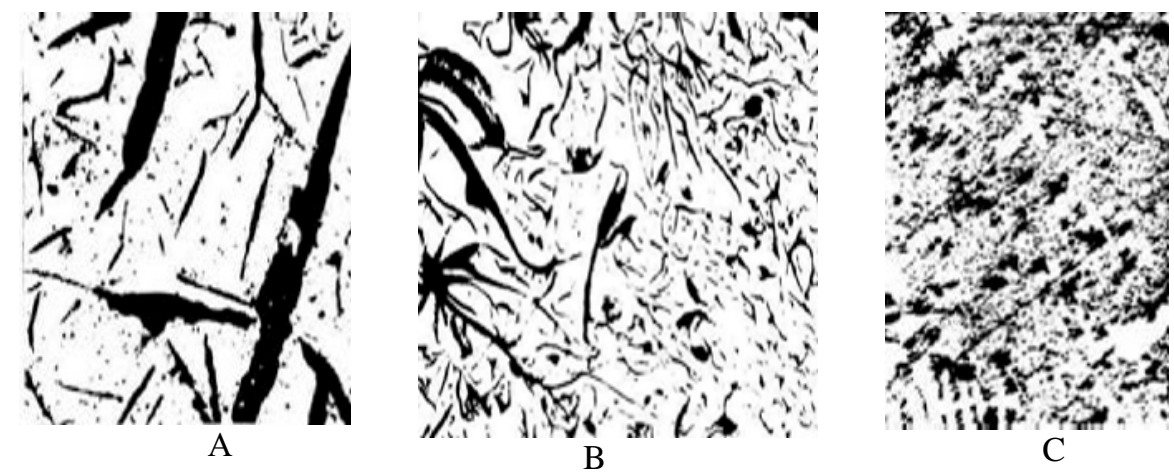

Fig. 4. The microstructure of the Fe-C-Si material after centrifugation during cooling with the furnace: A, B, C - microstructure research areas.

Silicon diffuses more slowly from the bottom of the ingot to the surface. So, the silicon concentration at the surface of the ingot is $2.74 \%$, and at the bottom $-2.16 \%$.

A change in the concentration of manganese during centrifugation is practically not observed. The content of harmful impurities (phosphorus and sulfur) at the bottom and on the surface of the ingot during centrifugation and slow cooling during crystallization varies significantly. So, in zone A at the surface, the total content of P and S is $0.117 \%$, and in zone B at the bottom $-0.033 \%$ (table 1 ).

Table 1. The chemical composition of the material of slowly cooled samples along the height of the ingot.

\begin{tabular}{|c|c|c|c|c|c|c|}
\hline \multirow[t]{2}{*}{ Zone number } & \multicolumn{5}{|c|}{$\begin{array}{l}\text { The chemical composition of materials based } \\
\text { on the Fe-C-Si system, weight \% }\end{array}$} & \multirow[t]{2}{*}{$\begin{array}{l}\text { Hardness, } \\
\text { HB }\end{array}$} \\
\hline & $\mathrm{C}$ & $\mathrm{Si}$ & $\mathrm{Mn}$ & $\mathrm{S}$ & $\mathrm{P}$ & \\
\hline A (at the surface) & 6.40 & 2.74 & 0.41 & 0.024 & 0.093 & 230 \\
\hline A (in the middle) & 5.2 & 2.20 & 0.39 & 0.018 & 0.071 & 220 \\
\hline B (at the bottom) & 3.00 & 2.16 & 0.37 & 0.012 & 0.021 & 160 \\
\hline
\end{tabular}

The accelerated cooling of materials based on the Fe-C-Si system from high temperatures (2073K) in air (Figure 5) also leads to a significant change in the structure and graphite inclusions. In the case under consideration, no large graphite inclusions were found near the surface of the ingot (zone A). As you move away from the surface (zone B), evenly spaced compact inclusions of graphite on a perlite-ledeburite base are observed. In some areas, compact graphite is bordered by ferrite.

In the bottom part of the ingot in zone A, the cooling rate was much lower, which led to the release of carbon in the form of vortex graphite inclusions. On the surface of the ingot (zone C), along with compact inclusions of graphite bordered by ferrite, the ledeburite and phosphide eutectics are clearly visible.

An analysis of the chemical composition of the impurities showed that during accelerated cooling of the melt from high temperatures (2073 K) after centrifugation, the difference in carbon concentration is much smaller than during slow cooling and ranges from $5.3 \%$ at the surface (zone A) to $4,7 \%$ at the bottom of the ingot (zone B).

At the same time, there is also a redistribution of silicon from $2.65 \%$ - at the surface to $2.20 \%$ - at the bottom. In addition, there is a significant redistribution of harmful impurities. For example, the total sulfur and phosphorus content at the surface of the ingot (zone A) was $0.113 \%$, and at the bottom (zone B) it was $0.043 \%$ (table 2 ). 


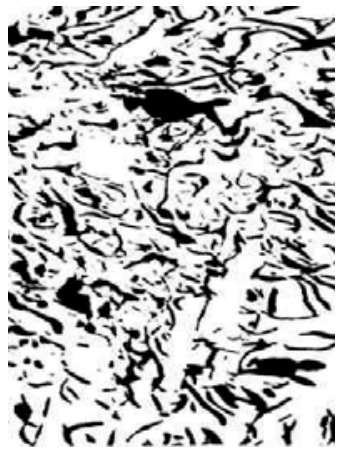

A

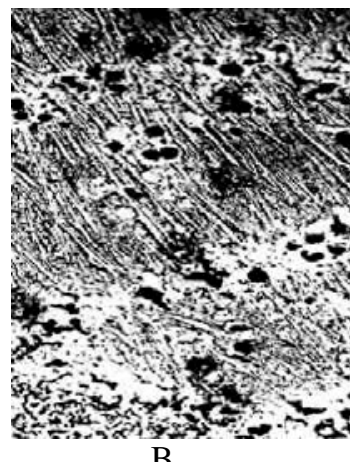

B

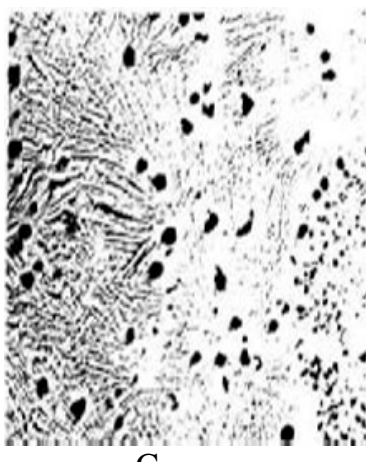

C

Fig. 5 - The microstructure of the Fe-C-Si material after centrifugation and cooling in air: A, B, C zones of the study of the microstructure

It is obvious that during centrifugation in a two-phase solid-liquid zone, austenite released from the melt, as a heavier phase, moves to the bottom of the ingot, and the carbon-enriched melt, on the contrary, moves to the surface.

The chemical composition of the material of samples cooled in air over the height of the ingot.

Table 2 Chemical composition of the material of samples cooled in air over the height of the ingot

\begin{tabular}{|c|c|c|c|c|c|}
\hline \multirow[t]{2}{*}{ Zone number } & \multicolumn{4}{|c|}{$\begin{array}{l}\text { The chemical composition of materials } \\
\text { based on the Fe-C-Si system, weight } \%\end{array}$} & \multirow[t]{2}{*}{$\begin{array}{l}\text { Hardness, } \\
\text { HB }\end{array}$} \\
\hline & $\mathrm{C}$ & $\mathrm{Si}$ & Mn & $\mathrm{S}+\mathrm{P}$ & \\
\hline A (at the surface) & 5.35 & 2.65 & 0.41 & 0.113 & 240 \\
\hline A (in the middle) & 5.13 & 2.41 & 0.40 & 0.074 & 230 \\
\hline B (at the bottom) & 4.7 & 2.20 & 0.38 & 0.043 & 200 \\
\hline
\end{tabular}

The obtained results of microstructure and chemical composition of materials based on the system Fe-C-Si during centrifugation under different conditions of melting and crystallization of ingots complement existing ideas about the causes and mechanisms of structure formation in materials based on the system Fe-C-Si. In particular it is established, when heated, melt and redistribution of impurities in the centrifuge process, the possible mechanism of formation of compact ordered zones pseudoterminal metastable stoichiometry. The formation of compact graphite of them in this case is possible due to optimal mode of supercooling of the melt. Thus, we can conclude that the thermodynamic potential of the compact graphitization can be created artificially not only by the introduction of modifiers, but also due to the redistribution of impurities.

The results of microstructural studies of samples bystrookupaemyh with high superheat (about $2073 \mathrm{~K}$ ) confirm the above theoretical conclusions.

In zones B and C by the rapid cooling observed in the smallest inclusions (in points) of graphite, which indicates the possibility of their formation via spinodal mechanism.

From literature data, it is known that spinodal decomposition can occur instantly, without an observed incubation period, which, in our opinion, is realized during forced cooling of the melt materials based on the Fe-C-Si system [3-5].

In the process of slow cooling during centrifugation, conditions are provided for the intense release of graphite below the liquidus temperature and its movement to the inner surface of the ingot during centrifugation. The different cooling rate along the height of the ingot during slow cooling during centrifugation provides, on the one hand, the separation of graphite inclusions of various sizes and shapes from the melt, as well as different rates of their redistribution (transfer to the surface of the ingot). 
The results of the studies also confirm the well-known theoretical ideas about the conditions that ensure the formation of globular graphite in materials based on the Fe-C-Si system [6,7].

In particular, it was shown that for the process of graphite spheroidization, it is first of all important to ensure the necessary overheating of the melt and a sufficient degree of supercooling during crystallization of the ingot. High overheating mainly serves to dissolve crystallization centers of plate graphite. These include inclusions of phosphides, nitrides, oxides, etc. In addition, during centrifugation, materials based on the Fe-C-Si system are purified from harmful impurities, thereby neutralizing their antiglobulizing effect [8].

An analysis of the obtained experimental results confirms that in order to obtain globular graphite in materials based on the Fe-C-Si system, it is first of all important to clean the melt of surface-active substances and, first of all, of oxygen, phosphorus and sulfur. Under ordinary conditions, for the studied composition of materials based on the Fe - C - Si system, the formation of globular graphite does not occur without the use of modifiers. Under centrifugation conditions, even during slow cooling during crystallization of materials based on the Fe-C-Si system, the release of globular graphite is observed. During accelerated cooling of the same melt composition, compact graphite is formed in the ingot zones more remote from the surface than during slow cooling

The obtained research results during centrifugation are necessary for the process of regulated structure formation in materials based on the Fe-C-Si system and can be used in specific technological developments in the production of workpieces from materials based on the Fe-C-Si system with a differentiated (composite) structure by the centrifugal method casting.

\section{Findings}

It has been established that the formation of compact forms of graphite in materials based on the $\mathrm{Fe}-\mathrm{C}-\mathrm{Si}$ system is possible while ensuring a sufficiently high crystallization rate during critical supercooling during centrifugation of the melt. It is shown that the thermodynamic potential for compact melt graphitization can be created not only through the introduction of modifiers, but also due to overheating, rather rapid supercooling and purification of the melt from impurities (phosphides, nitrides, oxides, etc.).

Thus, the results of studies of heat and mass transfer during centrifugation of materials based on the Fe-C-Si system are important express information on the mechanism and kinetics of structure formation in materials based on the Fe-C-Si system. This information is not only of theoretical interest, but also necessary for the implementation of applied solutions for the development of materials and technological processes for the production of workpieces from materials based on the Fe-C-Si system with improved properties.

\section{References}

1. R.A. Bikulov, L.M. Kotlyar, A mathematical model of the distribution of the mixture components in a cast iron melt during centrifugation (sedimentation), Materials of the International Scientific and Technical Conference "Innovative Engineering Technologies, Equipment and Materials - 2013" and the forum "Improving Competitiveness and energy efficiency of machine-building enterprises in the WTO.”, pp. 43-46 (2013)

2. E.N. Kornienko, A.G. Panov, A.B. Mazo, High temperature centrifugation of cast iron castings, Sat Proceedings of the ISTC. Young Science - to the New Millennium, pp. 122124 (1996)

3. K.P. Bunin, Yu.N. Taran, Cast iron structure (M: Metallurgy, 1972) 
4. I.N. Bogachev, Metallography of cast iron (Sverdlovsk: GNTI, 1962)

5. A.A. Zhukov, On the fluctuation mechanism of nucleation of graphitization centers in cast iron and steel, MiTOM, vol.3,pp.14-15,(1961)

6. R.L. Snezhnoy, On the theory of the formation of spherical graphite in cast iron, Foundry, vol.5, pp.12-12, (1980)

7. A.A. Zhukov, Theoretical foundations of graphitization of cast iron and the formation of structure of castings. The mechanical properties of cast iron, (M: Mechanical Engineering, 1978)

8. R.A. Bikulov, M.S. Kolesnikov, V.I. Astashchenko, F.G. Karikh, Multi-purpose cast iron production: composition development and process control (M .: Academia, 2009) 